\title{
Effect of nanoemulsified oils addition on rumen fermentation and fatty acid proportion in a rumen simulation technique
}

\author{
M. El-Sherbiny ${ }^{1,3}$, A. Cieślak ${ }^{1}$, J. Szczechowiak ${ }^{1}$, P. Kołodziejski ${ }^{2}$, P. Szulc ${ }^{1}$ \\ and M. Szumacher-Strabe $\left.\right|^{1,4}$ \\ Poznan University of Life Sciences \\ ${ }^{1}$ Department of Animal Nutrition and Feed Management \\ ${ }^{2}$ Department of Animal Physiology and Biochemistry \\ Wołyńska 33, 60-637 Poznań, Poland \\ ${ }^{3}$ National Research Centre, Department of Dairy Sciences \\ 33 Bohouth St., Dokki, 12622 Giza, Egypt
}

KEY WORDS: nanoemulsion, fish oil, soyabean oil, unsaturated fatty acids, in vitro, rumen, RUSITEC

Received: 2 February 2016

Revised: $\quad 1$ April 2016

Accepted: 20 May 2016

${ }^{4}$ Corresponding author:

e-mail: mstrabel@up.poznan.pl

\begin{abstract}
The present study was carried out to investigate the potential of different oils nanoemulsions on the modulation of fatty acid proportions and their effect on selected ruminal bacteria using four-fermenter RUSITEC units of 1 I capacity each. Four treatments were investigated: 1 . control group $(11 \mathrm{~g}$ of dried total mixed ration), 2. the control plus soyabean oil ( $5 \%$ on dry matter basis), 3. the control plus fish oil ( $5 \%$ on dry matter basis), and 4 . the control plus soyabean-fish oils blend ( $1: 1 \mathrm{v} / \mathrm{v} ; 5 \%$ on dry matter basis). All oils were in nanoemulsified form and were added directly to the RUSITEC fermenters during the 10-day-feeding process. The obtained results indicated that the use of the nanoemulsified oils didn't affect total bacterial count; however, the nanoemulsified fish and soyabean-fish oil blend treatments decreased $(P<0.002)$ the relative proportions of both Butyrivibrio fibrisolvens and Ruminococcus albus. A significant decrease $(P=0.035)$ in Butyrivibrio proteoclasticus was only noticed after the nanoemulsified soyabean-fish oil blend addition. Regarding the fatty acids in the fermentation fluid, the nanoemulsified oils increased significantly $(P<0.001)$ the proportions of oleic, linoleic and linolenic acids. In conclusion, nanoemulsified soyabean oil modulates the polyunsaturated fatty acids in ruminal cultures without the negative effect on rumen fermentation parameters.
\end{abstract}

\section{Introduction}

Modulation of fatty acid profile in the rumen is assigned to several factors including diet. Feeds supplemented with polyunsaturated fatty acid (PUFA) rich oils of either plant or marine origin were widely investigated in the last decades. It was estimated that they have an ability to change positively the rumen fatty acid proportions by affecting the activ- ity of rumen microorganisms (AbuGhazaleh and Ishlak, 2014; Boerman and Lock, 2014). Further works illustrated the ability of fish oil supplemented up to $4.17 \mathrm{~g} \cdot \mathrm{l}^{-1}$ to inhibit the rumen biohydrogenation of linoleic acid and linolenic acid in a ruminal culture which consequently increases the accumulation of trans-11 C18:1 (Wąsowska et al., 2006). However, oil supplementation has some dietary limitations due to the possible negative impact on 
rumen fermentation (Martínez Marín et al., 2013; Ishlak et al., 2014). On the other hand, rumen lipolysis and biohydrogenation act as barriers that prevent an easy transfer of the dietary PUFA to milk (Lanier and Corl, 2015). Rumen bacteria biohydrogenate toxic dietary unsaturated fatty acids (UFA) to saturated fatty acid (SFA) in order to protect their cellular construction. This mechanism results in a higher outflow of SFA to the small intestine for digestion and absorption (Beam et al., 2000; Boerman and Lock, 2014). So, it is desirable to find other forms of supplemented oils that could preserve PUFA from being affected by rumen lipolysis and biohydrogenation, and could not have the negative effect on the rumen fermentation and the cellular construction of the rumen microorganisms at the same time.

Recently, nanotechnology has found innumerable applications in many different areas. Delivery of bioactive components using nanoscale technology has been documented not only in pharmaceutics but also in the cosmetic and food sciences (Fathi et al., 2012; Ghosh et al., 2014; Zhang et al., 2014). Nanoemulsion is one of the most important nanotechnology applications with a wide usage in several scientific and practical fields. Nanoemulsion is defined as multiphase colloidal dispersions formed by a mixture of one liquid that is dispersed as nanoscale droplets in another immiscible liquid. Physical share-induced rupturing leads to a droplet's diameter that is less than $100 \mathrm{~nm}$ (Mason et al., 2006). In a previous investigation (El-Sherbiny et al., 2016) nanoemulsified form of edible oil blends preserved higher proportion of UFA from being hydrogenated in ruminal batch cultures compared to the same level of raw oils addition. In the present study, we hypothesized that nanoscale droplets of oil blends rich in PUFA, added directly to the rumen fermentation culture in the RUSITEC system, would probably inhibit the microbial reactions, i.e. lipolysis and biohydrogenation without affecting the total microbial population. This inhibition could preserve more UFA from being lost during those processes. Therefore, the main objective is to investigate the effects of different nanoemulsified oils rich in UFA (mainly PUFA) as a novel dietary component on the modulation of rumen fatty acid and the rumen microbial population in a long-term ruminal fermentation culture (RUSITEC).

\section{Material and methods}

\section{Nanoemulsified oils preparation}

The oil-in-water nanoemulsion was prepared using a HIELSCHER UP50H ultrasonic processor $(80 \%$ amplitude for $20 \mathrm{~min}$; Hielscher Ultrasonics, Teltow,
Germany) as described by Lakalayeh et al. (2012). Soyabean oil, fish oil and their 1:1 (v/v) blend were used as the inner phase, Tween 80 (Sigma-Aldrich, St. Louis, MO, USA) was used as the only surfactant. The oil-in-water emulsion formulation was composed of $15 \%$ oil, $5.6 \%$ Tween 80 and $79.4 \%$ deionized water as was suggested by Kentish et al. (2008).

\section{Equipment and experimental design}

The study was carried out using rumen simulation technique equipment (RUSITEC) as developed by Czerkawski and Breckenridge (1977). The RUSITEC system consisted of four fermenters, each of 11 capacity placed in a water bath maintained at $39^{\circ} \mathrm{C}$ throughout the experiment. The rumen inoculum was obtained from 3 ruminal cannulated Polish Holstein-Friesian dairy cows (body weight of $600 \pm 25 \mathrm{~kg}$, month 4 of lactation) $3 \mathrm{~h}$ after the morning feeding. Rumen donor cows were fed $20.5 \mathrm{~kg}$ of dry matter (DM) per day of total mixed ration (TMR), similar to the diet used in the in vitro experiment. The ruminal content was collected from the top, bottom and middle part of the rumen of each cow separately. The ruminal contents from all cows were equally blended, strained through four layers of gauze into a Schott Duran ${ }^{\circledR}$ bottle (SCHOTT North America, Inc., Elmsford, NY, USA), and immediately transported to the laboratory in a $39^{\circ} \mathrm{C}$ preheated water bath. On the first day of each experimental run, each fermenter was filled with $900 \mathrm{ml}$ of strained rumen fluid and $100 \mathrm{ml}$ of pre-warmed McDougall buffer (McDougall, 1948) achieving a final $\mathrm{pH}$ of the incubation mixture between 6.9 and 7.1. Moreover, two nylon bags: one filled with $11 \mathrm{~g}$ of solid rumen content and the other filled with $11 \mathrm{~g}$ of the control diet on DM basis, were put in a perforated feed container and placed in the respective fermenter. The nylon bags $(70 \mathrm{~mm} \times 140 \mathrm{~mm})$ of a $100 \mu \mathrm{m}$ pore size as cited by Soliva and Hess (2007) were used in the study. After $24 \mathrm{~h}$ of incubation, the nylon bag containing solid rumen content was replaced with a nylon bag containing the control diet. Each feed bag was therefore incubated for $48 \mathrm{~h}$. To immediately re-establish the anaerobic conditions in the gaseous phase of the fermenters, gaseous nitrogen was flushed through the incubation units for $3 \mathrm{~min}\left(3 \mathrm{l} \cdot \mathrm{min}^{-1}\right)$, each time after closing the system. During the experimental runs, artificial saliva (McDougall, 1948) was infused continuously into every fermenter at an average buffer flow rate of $500 \mathrm{ml}$ per day. To guarantee a constant buffer flow an electronic peristaltic pump (Miniplus 3; Gilson, Inc., Middleton, WI, USA) was used. Liquid effluent was automatically transferred 
through an overflow tube to the respective effluent vessels containing $10 \mathrm{ml}$ of $6 \mathrm{~N} \mathrm{HCl}$ to stop the fermentation process.

The experiment was arranged in a completely randomized block design with 4 treatments and 3 repetitions (10 days each), using a four-fermenter RUSITEC system. The experimental groups were as follows: 1 . CON - control group (11 $\mathrm{g}$ of dried total mixed ration), 2. NES - the control + soyabean oil ( $5 \%$ on DM basis), 3 . NEF - the control + fish oil ( $5 \%$ on DM basis), and 4. NEB - the control + soyabeanfish oils blend ( $1: 1 \mathrm{v} / \mathrm{v} ; 5 \%$ on DM basis). The oils were used in nanoemulsified form. The substrate used in the experiment was similar to the diet offered to the ruminal cannulated dairy cows (rumen fluid donors). All ingredients were dried and then milled separately. A homogenous mixture of the experimental substrate was made on DM basis by mixing together the following amounts of the dried ingredients $\left(\mathrm{g} \cdot \mathrm{kg}^{-1} \mathrm{DM}\right)$ : maize silage 396 , lucerne silage 71 , grass silage 104 , beet pulp 113, brewer's grain 85 , extracted rapeseed meal 42 , commercial concentrate containing $18 \%$ of crude protein 185 , and a mineral mixture 4 . The nanoemulsified oils (daily prepared) were calculated on DM basis and added directly to the RUSITEC fermenters during the 10-day-feeding process. The prepared nanoemulsified oils were intentionally added directly to the incubation fluids. The mixing it with the feed was avoided to simulate our initial idea of adding the nanoemulsion to the drinking water given to dairy cattle.

\section{Sampling and chemical analysis}

In 3 RUSITEC runs (10 days each) the data from the first 5 days was not considered in the statistical evaluation since the microbes in the RUSITEC system need $4-5$ days for adaptation (Soliva and Hess, 2007). The following 5 days represent the sampling period, where fermentation fluid samples were collected at each day $3 \mathrm{~h}$ before the new nylon feed bag addition. Collected fermentation fluid was analysed for $\mathrm{pH}$ value using a $\mathrm{pH}$ meter (CP-104; Elmetron, Zabrze, Poland) and ammonia concentration according to the colorimetric Nessler method modified by SzumacherStrabel et al. (2002). The total protozoan counts were determined according to the method described by Michalowski et al. (1986). Total bacterial counts were quantified by the method cited by Ericsson et al. (2000) using a Thoma counting chamber (Blau Brand $^{\circledR}$, Wertheim, Germany). The volatile fatty acids (VFA) in fermentation culture samples were determined by gas chromatography technique (GC Varian CP 3380, Sugarland, TX, USA) according to Tangerman and Nagengast (1996), with some modifications. Briefly, $3.6 \mathrm{ml}$ of the immediately collected rumen fluid sample was stabilized with $0.4 \mathrm{ml}$ of a $46 \mathrm{mM} \mathrm{HgCl}$ solution and frozen $\left(-20{ }^{\circ} \mathrm{C}\right)$ until analysis by gas chromatograph fitted with flame ionization detector (FID) and capillary column $30 \mathrm{~m} \times 0.25 \mathrm{~mm}(19091 \mathrm{~N}-133$; Agilent HPInnowax, Agilent Technologies, Santa Clara, CA, USA). The qualitative and quantitative identification of VFA peaks was made by mixing individual VFA purchased from Fluka (Sigma Aldrich, St. Louis, MO, USA) using MS Work Station 5.0 (Agilent Technologies, Santa Clara, CA, USA).

Fatty acid methyl esters in the total mixed ration, nanoemulsions and fermentation fluid samples (Table 1) were extracted and analysed according to Cieślak et al. (2015) with some modifications. Briefly, $2500 \mu \mathrm{l}$ of rumen fluid was suspended in $3 \mathrm{ml}$ of $2 \mathrm{M} \mathrm{NaOH}$ and incubated in a block heater at $90{ }^{\circ} \mathrm{C}$ for $40 \mathrm{~min}$. After cooling to room temperature, $1.7 \mathrm{ml}$ of $4 \mathrm{M} \mathrm{HCl}$ was added to lower the $\mathrm{pH}$ below 2. Before extraction, $2 \mathrm{ml}$ of distilled diethyl ether was added to each sample. The tubes were vigorously shaken for $10 \mathrm{~min}$ and then centrifuged

Table 1. Fatty acid (FA) proportion in total mixed ration and supplemented nanoemulsions, $\mathrm{g} \cdot 100 \mathrm{~g}$ FA

\begin{tabular}{lcccc}
\hline \multirow{2}{*}{ Fatty acid } & \multirow{2}{*}{ CON $^{1}$} & \multicolumn{3}{c}{ Supplement $^{2}$} \\
\cline { 3 - 5 } & & NES & NEF & NEB \\
\hline C12:0 & 0.31 & 0.32 & 0.26 & 0.40 \\
C14:0 & 0.62 & 0.26 & 2.37 & 1.28 \\
C16:0 & 20.8 & 9.82 & 9.36 & 9.99 \\
C18:0 & 2.41 & 5.41 & 2.97 & 5.19 \\
cis-9 C18:1 & 19.5 & 28.8 & 43.2 & 34.6 \\
cis-9 cis-12 C18:2 & 40.7 & 42.0 & 12.3 & 26.5 \\
cis-9 cis-12 cis-15 C18:3 & 7.26 & 6.41 & 4.54 & 5.30 \\
C20:5n-3 & nd & nd & 0.25 & 0.14 \\
C22:6n-3 & nd & nd & 4.32 & 1.93 \\
SFA & 26.6 & 17.0 & 16.5 & 18.3 \\
UFA $^{4}$ & 73.4 & 82.9 & 83.5 & 81.7 \\
MUFA $^{5}$ & 49.9 & 50.7 & 31.5 & 40.9 \\
PUFA $^{6}$ & 23.4 & 32.2 & 51.9 & 40.7 \\
n-6 & 42.4 & 43.2 & 17.8 & 30.6 \\
n-3 & 7.53 & 6.55 & 11.4 & 8.83 \\
n-6/n-3 & 5.62 & 6.59 & 1.57 & 3.48 \\
\hline
\end{tabular}

${ }^{1} \mathrm{CON}$ - control treatment consisted of total mixed ration used as the main substrate; ${ }^{2}$ supplements: NES - nanoemulsified soyabean oil; NEF - nanoemulsified fish oil; NEB - nanoemulsified soyabean - fish oil 1:1 blend; ${ }^{3}$ SFA - sum of saturated fatty acids (C6, C8, C10, C12, $\mathrm{C} 14, \mathrm{C} 15, \mathrm{C} 16, \mathrm{C} 17, \mathrm{C} 18, \mathrm{C} 19, \mathrm{C} 20, \mathrm{C} 22, \mathrm{C} 24) ;{ }^{4} \mathrm{UFA}$ - sum of unsaturated fatty acids (C10:1, C14:1, C15:1, C16:1, C17:1, c9C18:1, c11C18:1, c12C18:1, c9c12C18:2, c9c15C18:2, c9c12c15C18:3, C20:1n-9, C20:3n-3, C20:4n-6, C20:5n-3, C22:1n-9, C22:2, C22:5n-3, C22:6n-3, C24:1); ${ }^{5}$ PUFA - sum of polyunsaturated fatty acids (c9c12C18:2, c9c15C18:2, c9c12c15C18:3, C20:3n-3, C20:4n-6, C20:5n-3, C22:2, C22:5n-3, C22:6n-3); ${ }^{6}$ MUFA - sum of monounsaturated fatty acids (C10:1, C14:1, C16:1, C17:1, c9C18:1, C11C18:1, c12C18:1, C20:1n-9, C22:1n-9, C24:1); nd - not detected 
at $6160 \mathrm{~g}$ for $1 \mathrm{~min}$ at $20^{\circ} \mathrm{C}$. The extraction procedure was repeated 3 times, and the supernatant was finally evaporated at $30{ }^{\circ} \mathrm{C}$ for 10 min under a flux of nitrogen using a Techne Dri-Block heater Model DB-3 (Bibby Scientific Ltd., Staffordshire, UK). The preparation of the fatty acid methyl esters (FAME) was carried out according to the IUPAC (1987) method 2.301 with slight modification. The extract was boiled with $2 \mathrm{ml}$ of $\mathrm{NaOH}$ in methanol $(0.5 \mathrm{M})$ for $3 \mathrm{~min}$, then $3 \mathrm{ml}$ of boron trifluoride-methanol (1.3 M; Fluka - Sigma Aldrich, St. Louis, MO, USA) was added to the solution. As a final step, the solution was reheated for $4 \mathrm{~min}$, and then the reaction was terminated by adding $7 \mathrm{ml}$ of $\mathrm{NaCl}(0.34 \mathrm{M})$ and $1 \mathrm{ml}$ of hexane. This mixture was shaken vigorously. The organic phase containing the FAME was used for gas chromatographic analyses using a GC-BRUKER SCION-456-GC (Bruker Corporation, Billerica, MA, USA), equipped with FID and a fused-silica capillary column Chrompack CP7420 (length $100 \mathrm{~m}$, inner diameter $0.25 \mathrm{~mm}$, film thickness $0.25 \mu \mathrm{m}$; Agilent HP, Agilent Technologies, Santa Clara, CA, USA). Hydrogen was used as the carrier gas at a flow rate $1.3 \mathrm{ml} \cdot \mathrm{min}^{-1}$. Injector and detector temperatures were $200{ }^{\circ} \mathrm{C}$ and $250{ }^{\circ} \mathrm{C}$, respectively. The oven temperature programmes: initially $120^{\circ} \mathrm{C}$ for $7 \mathrm{~min}$, then increased by $7{ }^{\circ} \mathrm{C} \cdot \min ^{-1}$ to $140{ }^{\circ} \mathrm{C}$, holding for $10 \mathrm{~min}$ and then increased by $4{ }^{\circ} \mathrm{C} \cdot \mathrm{min}^{-1}$ to $240^{\circ} \mathrm{C}$. Sample $(1 \mu \mathrm{l})$ was injected into the column. Fatty acids were identified based on their retention times and were expressed as a $\mathrm{g} \cdot 100 \mathrm{~g}^{-1}$ FA. Fatty acid peaks were identified by comparison with the standard retention times (37 FAME Mix, Supelco, Poole, England) and cis-9 trans-11 C18:2 (Matreya, Pleasant Gap, PA, USA).

The quantities of some selected rumen bacteria (Butyrivibrio fibrisolvens, Butyrivibrio proteoclasticus and Ruminococcus albus) were determined by DNA isolation from rumen fluid according to $\mathrm{Yu}$ and Morrison (2004). Briefly, total DNA from rumen fluid was extracted with a Mini Bead-Beater (BioSpec Products, Bartlesville, OK, USA) for cell lysis. Rumen fluid in the amount of $4 \mathrm{ml}$ was used for DNA extraction and an additional DNA purification step was included (QIAamp DNA Stool Mini Kit; Qiagen, Hilden, Germany). DNA concentration was measured with NanoDrop 2000 spectrophotometer (Thermo Scientific, Wilmington, DE, USA). The DNA used for this experiment has to possess an A260:A280 ratio higher than 1.8. The primer pairs for $B$. fibrisolvens ( $\mathrm{F}$ : ACACACCGCCCGTCACA R: CCTTAC GGTTGGGTCACAGA), B. proteoclasticus (F: TCCTAGTGTAGCGGTGAAATG R: TTAGCGACGGCACTGAATGCCTA) and for
R. albus (F: CCCTAAAAGCAGTCTTAGTTCG

R: CCTCCTTGCGGTTAGAACA) were described by $\mathrm{Li}$ et al. (2009), Potu et al. (2011) and Wang et al. (1997), respectively. The primer pairs for total bacteria (F: GTGSTGCAYGGYTGTCGTCA R: GAGGAAGGTGKGGAYGACGT) were described by Maeda et al. (2003). The specificity of primers was confirmed using the BLAST programme in the GenBank Database. The starting DNA concentration for detection of selected ruminal bacteria was $10 \mathrm{ng}$ per $25 \mu \mathrm{l}$. The quantification of each bacterial species DNA and total bacteria in total rumen DNA was performed with a QuantStudio 12 Flex PCR system (Life Technologies - Thermo Fisher Scientific, Waltham, MA, USA). The Power SYBR GREEN PCR Master mix (Thermo Fisher Scientific, Waltham, MA, USA) was used for PCR amplification. The reaction mixture in $20 \mu \mathrm{l}$ of the final volume contained $5 \mu \mathrm{l}$ of the $2 \times$ Mastermix, $10 \mathrm{ng}$ of template DNA and $0.5 \mu \mathrm{M}$ of each primer. Amplification involved one cycle at $95{ }^{\circ} \mathrm{C}$ for $10 \mathrm{~min}$ for initial denaturation and then 45 cycles of $95^{\circ} \mathrm{C}$ for $15 \mathrm{~s}$ followed by annealing at the temperatures (depends on analysed bacteria) for $5 \mathrm{~s}$ and then at $62{ }^{\circ} \mathrm{C}$ for $67 \mathrm{~s}$. Detection of the fluorescent product was set at the last step of each cycle. To determine the specificity of amplification, analysis of product melting was performed after single amplification $\left(0.1^{\circ} \mathrm{C} \cdot \mathrm{s}^{-1}\right.$ increment from $65{ }^{\circ} \mathrm{C}$ to $95{ }^{\circ} \mathrm{C}$ with fluorescence collection at $0.1{ }^{\circ} \mathrm{C}$ intervals). Additional product size verification by gel electrophoresis of samples after the PCR run was included. Dilution of purified genomic DNA from control strains was used to construct species-specific calibration curves. Calibration curve was used for calculation of the species-specific DNA concentration in total rumen DNA preparations (number of DNA copies). The relative level of DNA copy of each bacteria species was calculated using the formula $2^{-\Delta \Delta C t}$, as a reference total bacteria DNA level was used.

\section{Statistical analysis}

Measurements (e.g., rumen microbial population, parameters of rumen fermentation) were obtained from the RUSITEC from days 6 to 10. Each run was considered a random block and for all variables the vessel was considered to be the experimental unit. Data was analysed using a mixed model procedure by SAS software (version 9.3; SAS Institute Inc., Cary, NC, USA), which included the fixed effects of treatment, run and their interactions. Differences among treatments were tested using the Tukey's post hock test. Data was accepted as statistically different if $P<0.05$. All values are shown as group means with pooled standard errors of means. 


\section{Results}

\section{Rumen fermentation parameters}

Total bacterial count, Entodiniomorpha and Holotricha protozoan counts were not affected by any of the nanoemulsified oils addition (Table 2). The used nanoemulsified oils treatments also did not exert influence on fermentation culture $\mathrm{pH}$ and ammonia concentration in comparison to the control diet. However, the inclusion of NEB to the fermentation culture decreased $(P<0.01)$ in vitro dry matter digestibility (IVDMD) and the total VFA content when compared to NES and the control diet. It was accompanied by the decrease $(P<0.02)$ in the molar proportions of both acetate and valerate by NEB supplementation.

Interestingly, NES addition had no effect $(P>0.05)$ on the relative proportions of Butyrivibriofibrisolvens, Butyrivibrio proteoclasticus and

Table 2. Effect of nanoemulsified oils supplementation on rumen basic parameters, volatile fatty acids and relative proportions of selected rumen bacteria in RUSITEC system

\begin{tabular}{|c|c|c|c|c|c|c|}
\hline \multirow{2}{*}{ Indices } & \multicolumn{4}{|c|}{ Treatment $^{1}$} & \multirow{2}{*}{ SEM } & \multirow{2}{*}{$P$} \\
\hline & $\mathrm{CON}$ & NES & NEF & NEB & & \\
\hline $\mathrm{pH}$ & 6.81 & 6.82 & 6.82 & 6.84 & 0.008 & 0.538 \\
\hline Ammonia, mM & 8.39 & 8.68 & 9.23 & 8.80 & 0.245 & 0.385 \\
\hline IVDMD² & $56.9^{\mathrm{a}}$ & $56.5^{\mathrm{a}}$ & $55.4^{\mathrm{ab}}$ & $53.5^{\mathrm{b}}$ & 0.330 & 0.004 \\
\hline \multicolumn{7}{|l|}{$V F A^{3}, m M$} \\
\hline total VFA & $91.3^{\mathrm{a}}$ & $94.4^{\mathrm{a}}$ & $90.5^{\mathrm{ab}}$ & $86.7^{b}$ & 0.767 & 0.003 \\
\hline acetate & $53.6^{\mathrm{ab}}$ & $56.1^{\mathrm{a}}$ & $53.1^{\mathrm{ab}}$ & $51.2^{\mathrm{b}}$ & 0.549 & 0.019 \\
\hline propionate & 15.6 & 15.8 & 15.6 & 14.9 & 0.132 & 0.117 \\
\hline isobutyrate & 1.37 & 1.52 & 1.25 & 1.29 & 0.035 & 0.163 \\
\hline butyrate & 13.9 & 14.0 & 13.8 & 13.1 & 0.186 & 0.366 \\
\hline isovalerate & 1.71 & 1.68 & 1.57 & 1.48 & 0.035 & 0.144 \\
\hline valerate & $5.12^{\mathrm{ab}}$ & $5.35^{\mathrm{a}}$ & $5.01^{\mathrm{ab}}$ & $4.67^{b}$ & 0.070 & 0.009 \\
\hline Acetate/propionate & 3.46 & 3.57 & 3.43 & 3.43 & 0.038 & 0.273 \\
\hline \multicolumn{7}{|c|}{ Rumen microorganisms enumeration ${ }^{4}$} \\
\hline $\begin{array}{l}\text { Entodiniomorpha, } \\
\text { cell } \times 10^{3} \cdot \mathrm{ml}^{-1}\end{array}$ & 3.50 & 3.84 & 3.91 & 3.68 & 0.180 & 0.737 \\
\hline $\begin{array}{l}\text { Holotricha, } \\
\text { cell } \times 10^{2} \cdot \mathrm{ml}^{-1}\end{array}$ & 1.07 & 1.07 & 1.09 & 1.16 & 0.050 & 0.949 \\
\hline $\begin{array}{l}\text { Total bacteria, } \\
\text { cell } \times 10^{8} \cdot \mathrm{ml}^{-1}\end{array}$ & 7.11 & 6.96 & 6.41 & 6.76 & 0.200 & 0.432 \\
\hline \multicolumn{7}{|c|}{ Selected rumen bacteria ${ }^{5}$} \\
\hline $\begin{array}{l}\text { Butyrivibrio } \\
\text { fibrisolvens }\end{array}$ & $0.024^{\mathrm{a}}$ & $0.028^{a}$ & $0.017^{b}$ & $0.016^{b}$ & 0.0004 & 0.040 \\
\hline $\begin{array}{l}\text { Butyrivibrio } \\
\text { proteoclasticus }\end{array}$ & $0.020^{\mathrm{a}}$ & $0.014^{a}$ & $0.013^{a}$ & $0.011^{b}$ & 0.0012 & 0.035 \\
\hline
\end{tabular}

$\begin{array}{lllllll}\text { Ruminococcus albus } & 0.039^{\mathrm{a}} & 0.033^{\mathrm{a}} & 0.026^{\mathrm{b}} & 0.023^{\mathrm{b}} & 0.0018 & 0.003\end{array}$ $\begin{array}{lllllll}\begin{array}{c}\text { Total bacteria, arbitrary } \\ \text { units }\end{array} & 1.00 & 0.98 & 1.01 & 1.03 & 0.0350 & 0.530\end{array}$

${ }^{1}$ see Table $1 ;{ }^{2}$ IVDMD - in vitro dry matter digestibility; ${ }^{3} \mathrm{VFA}$ - volatile fatty acid; ${ }^{4}$ total count of selected rumen microorganisms using light microscope; ${ }^{5}$ effect of diets on relative proportions (\% of total bacteria) of each population; abc - means with different superscripts within a row are significantly different $(P<0.05)$
Table 3. Effect of nanoemulsified oils supplementation on rumen fatty acid (FA) proportion in RUSITEC system, $\mathrm{g} \cdot 100 \mathrm{~g}^{-1} \mathrm{FA} ; P<0.001$

\begin{tabular}{|c|c|c|c|c|c|}
\hline \multirow{2}{*}{ Fatty acid } & \multicolumn{4}{|c|}{ Treatment $^{1}$} & \multirow{2}{*}{ SEM } \\
\hline & $\mathrm{CON}$ & NES & NEF & NEB & \\
\hline $\mathrm{C} 8: 0$ & $1.04^{a}$ & $0.15^{b}$ & $0.15^{b}$ & $0.16^{b}$ & 0.036 \\
\hline C10:0 & $0.69^{a}$ & $0.09^{b}$ & $0.09^{b}$ & $0.09^{b}$ & 0.027 \\
\hline C12:0 & $3.37^{\mathrm{a}}$ & $0.38^{b}$ & $0.48^{b}$ & $0.39^{b}$ & 0.119 \\
\hline $\mathrm{C} 14: 0$ & $2.71^{\mathrm{a}}$ & $0.56^{c}$ & $2.09^{a}$ & $1.35^{b}$ & 0.076 \\
\hline cis-9 C14:1 & $1.04^{\mathrm{a}}$ & $0.13^{c}$ & $0.19^{b}$ & $0.13^{c}$ & 0.036 \\
\hline C16:0 & $18.5^{\mathrm{a}}$ & $11.1^{b}$ & $11.0^{\mathrm{b}}$ & $11.0^{\mathrm{b}}$ & 0.268 \\
\hline cis-9 C16:1 & $1.02^{c}$ & $0.32^{b}$ & $1.85^{\mathrm{a}}$ & $1.13^{b}$ & 0.053 \\
\hline C18:0 & $28.1^{\mathrm{a}}$ & $16.2^{b}$ & $14.3^{b}$ & $15.9^{b}$ & 0.534 \\
\hline trans-10 C18:1 & $1.96^{\mathrm{a}}$ & $0.29^{\circ}$ & $0.39^{b}$ & $0.35^{\mathrm{bc}}$ & 0.058 \\
\hline trans-11 C18:1 & $2.03^{a}$ & $0.43^{c}$ & $0.69^{b}$ & $0.56^{\mathrm{b}}$ & 0.052 \\
\hline cis-9 C18:1 & $5.10^{d}$ & $22.3^{c}$ & $30.9^{a}$ & $26.5^{\mathrm{b}}$ & 0.814 \\
\hline cis-9 cis-12 C18:2 & $2.65^{d}$ & $32.5^{\mathrm{a}}$ & $11.5^{c}$ & $21.8^{b}$ & 0.928 \\
\hline cis- 9 cis-12 cis-15 C18:3 & $1.25^{d}$ & $5.00^{\mathrm{a}}$ & $3.60^{c}$ & $4.31^{b}$ & 0.116 \\
\hline cis-9 trans- 11 C18:2 & $0.56^{\mathrm{a}}$ & $0.47^{\mathrm{ab}}$ & $0.27^{\circ}$ & $0.33^{b}$ & 0.024 \\
\hline trans-10 cis-12 C18:2 & $0.55^{\mathrm{a}}$ & $0.29^{\mathrm{ab}}$ & $0.26^{b}$ & $0.18^{c}$ & 0.022 \\
\hline$C 20: 5 n-3$ & nd & nd & $0.18^{\mathrm{a}}$ & $0.11^{b}$ & 0.006 \\
\hline$C 22: 5 n-3$ & nd & nd & $1.16^{a}$ & $0.62^{b}$ & 0.039 \\
\hline$C 22: 6 n-3$ & nd & nd & $3.13^{\mathrm{a}}$ & $1.62^{b}$ & 0.105 \\
\hline $\mathrm{SFA}^{2}$ & $71.2^{\mathrm{a}}$ & $32.5^{b}$ & $31.0^{\mathrm{b}}$ & $32.7^{\mathrm{b}}$ & 1.396 \\
\hline $\mathrm{UFA}^{3}$ & $28.8^{b}$ & $67.5^{\mathrm{a}}$ & $68.9^{a}$ & $67.3^{\mathrm{a}}$ & 1.396 \\
\hline MUFA $^{4}$ & $18.9^{d}$ & $27.2^{\mathrm{c}}$ & $40.7^{\mathrm{a}}$ & $33.2^{b}$ & 0.713 \\
\hline PUFA $^{5}$ & $9.91^{d}$ & $40.3^{\mathrm{a}}$ & $28.2^{c}$ & $34.1^{\mathrm{b}}$ & 0.932 \\
\hline UFA/SFA & $0.42^{b}$ & $2.12^{\mathrm{a}}$ & $2.95^{\mathrm{a}}$ & $2.14^{a}$ & 0.167 \\
\hline Total trans $\mathrm{C} 18: 1$ & $4.73^{\mathrm{a}}$ & $2.59^{c}$ & $3.36^{\mathrm{b}}$ & $2.72^{b}$ & 0.452 \\
\hline $\mathrm{MCFA}^{6}$ & $28.8^{\mathrm{a}}$ & $13.1^{\mathrm{d}}$ & $16.7^{\mathrm{b}}$ & $14.7^{c}$ & 0.511 \\
\hline LCFA $^{7}$ & $57.7^{c}$ & $83.8^{\mathrm{a}}$ & $80.6^{b}$ & $82.2^{\mathrm{a}}$ & 0.887 \\
\hline$n-6$ & $6.53^{c}$ & $33.9^{a}$ & $17.4^{\mathrm{b}}$ & $25.5^{\mathrm{a}}$ & 0.842 \\
\hline$n-3$ & $2.65^{d}$ & $5.51^{c}$ & $9.58^{\mathrm{a}}$ & $7.61^{b}$ & 0.224 \\
\hline$n-6 / n-3$ & $3.01^{\mathrm{b}}$ & $6.31^{a}$ & $1.85^{\circ}$ & $3.35^{b}$ & 0.145 \\
\hline
\end{tabular}

${ }^{1}$ see Table $1 ;{ }^{2}$ SFA - sum of saturated fatty acids (C6, C8, C10, C12, C12iso, C12aiso, C13iso, C14, C14iso, C14aiso, C15, C15iso, C16, C16iso, C16aiso; C17, C17iso, C17aiso, C18,C19, C20, C22, C24); ${ }^{3}$ UFA - sum of unsaturated fatty acids (C10:1, C14:1, C15:1, C16:1, C17:1, t5C18:1, t6-8C18:1, t9C8:1, t10C18:1, t11C18:1, t12C18:1, t15C18:1, c9C18:1, c11C18:1, c12C18:1, c13C18:1, c14C18:1, c15C18:1, t10c12C18:2, c9t12C18:2, c9c12C18:2, c9c15C18:2, c9c12c15C18:3, C20:1n-9, C20:3n-3, C20:4n-6, C20:5n-3, C22:1n-9, C22:2, C22:5n-3, C22:6n-3, C24:1); ${ }^{4}$ MUFA - sum of monounsaturated fatty acids (C10:1, C14:1, C15:1, C16:1, C17:1, t5C18:1, t6-8C18:1, t9C18:1, t10C18:1, t11C18:1, t12C18:1, t15C18:1, c9C18:1, c11C18:1, c12C18:1, c13C18:1, c14C18:1, c15C18:1, C20:1n-9, C22:1n-9, $\mathrm{C} 24: 1) ;{ }^{5}$ PUFA - sum of polyunsaturated fatty acids (t10c12C18:2, c9t12C18:2, c9c12C18:2, c9c15C18:2, c9c12c15C18:3, C20:3n-3, $\mathrm{C} 20: 4 n-6, C 20: 5 n-3, C 22: 2, C 22: 5 n-3, C 22: 6 n-3) ;{ }^{6}$ MCFA = sum of medium chain fatty acids (C12, C12iso, C12aiso, C13iso, C14, C14iso , C14aiso, C14:1, C15, C15iso, C15:1, C16, C16iso, C16aiso, C16:1); ${ }^{7}$ LCFA = sum of long chain fatty acids (C17, C17iso, C17aiso, C17:1, C18, t5C18:1, t6-8C18:1, t9C8:1, t10C18:1, t11C18:1, t12C18:1, t15C18:1, c9C18:1, c11C18:1, c12C18:1, c13C18:1, c14C18:1, c15C18:1, t10c12C18:2, c9t12C18:2, c9c12C18:2, c9c15C18:2, c9c12c15C18:3, C19, C20, C20:1n-9, C20:3n-3, C20:4n-6, C20:5n-3, C22, C22:1n-9, C22:2, C22:5n-3, C22:6n-3, C24, C24:1); abc - means with different superscripts within a row are significantly different $(P<0.05)$; nd - not detected 
Ruminococcus albus compared to the control treatment. NEF and NEB supplementation decreased $(P<0.05)$ the relative proportions of both $B$. fibrisolvens and $R$. albus. A significant decrease $(P=0.035)$ in $B$. proteoclasticus was only noticed with NEB addition.

\section{Rumen fatty acids proportion}

Supplementing nanoemulsified oils in RUSITEC fermentation culture decreased $(P<0.001)$ vaccenic acid (trans-11 C18:1) proportion, which was severely reduced when nanoemulsified soyabean oil was added (Table 3). Similarly, cis-9 trans-11 C18:2 proportion was decreased significantly $(P<0.001)$ when the fish oil and oils blend nanoemulsion were added in comparison to the control treatment.

Regarding C18 UFA, supplementation of the nanoemulsified oils contributed in a vast significant increase in oleic acid (cis-9 C18:1), linoleic acid (cis-9 cis-12 C18:2) and linolenic acid (cis-9 cis-12 cis-15 C18:3) proportions as compared to the control group. Eicosapentaenoic acid (EPA) and docosahexaenoic acid (DHA) proportions were significantly higher $(P<0.001)$ with NEF compared to the NEB additions. Nanoemulsified oils reduced particular UFA to a lesser extent showing a higher proportion $(P<0.001)$ of UFA, especially PUFA, when compared to the proportion of SFA, which decreased $(P<0.001)$ by all types of nanoemulsified oils. The highest proportions of preserved PUFA, long chain FA and n-6 fatty acids were found when NES was added. In line with the preservation of more UFA on the expenses of SFA, a significant increase $(P<0.001)$ of UFA/SFA ratio was observed when nanoemulsified oils were applied.

\section{Discussion}

In the last decades, several studies were conducted mainly to illustrate the role of oil supplementation on the rumen biohydrogenation. Most of the results positively highlighted the role of supplemented oils on different rumen parameters; however, some negative impacts like decreased fibre digestion and milk fat depression were noted as well (Hellwing et al., 2012; Storlien et al., 2012; Patra and Yu, 2013; Morsy et al., 2015). In the present study, nanoemulsified oils were introduced as possibly having less impact on the rumen fermentation characteristics with better effect on preserving PUFA in the biohydrogenation environment.

In a previous investigation (El-Sherbiny et al., 2016) nanoemulsified oil blends (soyabean-fish oil blend or rapeseed-fish oil blend) tended to favourably increase the proportion of the preserved in vitro UFA, especially PUFA, as compared to the same level of raw oils blend addition. Such findings suggested that this alternative form of edible oils has the ability to preserve higher proportions of PUFA, which would be available for absorption regardless of the oil type used. However, not enough data was available to suggest a proper mode of action of oils blend nanoemulsion or single oil nanoemulsion (oil used for the blend preparation) and their effect on the different fermentation parameters. Precisely for these reasons, the present study was performed in the long-term in vitro experiment and the experimental treatments were based on the results obtained in the previous study by El-Sherbiny et al. (2016), who observed the addition of nanoemulsified soyabeanfish oil blend at the level of $5 \%$ of the substrate DM as the most beneficial in rumen nutrition.

Several studies suggested that fish oil could have a minor effect on rumen fermentation when supplemented in a small amount (AbuGhazaleh and Ishlak, 2014; Cieślak et al., 2015). However, above a certain threshold, fish oil supplementation could severely affect the rumen fermentation especially the relative proportions of gluconeogenic and acetogenic fermentation end products (Shingfield et al., 2012). The fish oil inclusion of different fatty acid composition as cited by Shingfield et al. (2010) could lead to a decrease in the molar concentration of the acetate toward the increased concentration of propionate. Propionate-producing gram-negative bacteria are not significantly inhibited by the fatty acids (O'Brien et al., 2014), which could explain the lack of effect of the nanoemulsions containing fish oil on the molar proportions of propionate in the current study. The possible decrease in molar concentration of acetate caused by fish oil fatty acid could explain the decrease observed in total volatile fatty acid count by NEF and NEB supplementation. In spite of the decrease, this effect seems to be significant $(P<0.01)$ only when NEB was added, which was probably due to the accompanied decrease in the in vitro dry matter digestibility and valerate molar proportions by NEB supplementation. Generally, it is suggested in the literature that the impact of fish oil on rumen fermentation is related mainly to several factors like the source and inclusion rate of fish oil, the intake potential, and composition of the diet (Shingfield et al., 2010). In the present study, the changes obtained in the relative proportions of the selected rumen bacteria are mostly related to the presence of fish oil which is rich in DHA inhibiting the activity of microorganisms (AbuGhazaleh and Ishlak, 2014). Reduced populations of B. fibrisolvens 
and $R$. albus in NEF group, and B. fibrisolvens, $B$. proteoclasticus and $R$. albus in NEB group were influenced mainly by the presence of long chain FA, especially EPA and DHA. Maia et al. (2010) examined the effect of added PUFA (linoleic acid, EPA and DHA) on the growth of biohydrogenation bacteria. In this study EPA and DHA were effective in decreasing the growth of B. fibrosolvens JW11. Moreover, Wąsowska et al. (2006) evaluated the effect of fish oil, EPA and DHA in ruminal cultures on the linoleic and linolenic acids disappearance, and examined the growth and isomerase activity of $B$. fibrisolvens. Their findings showed that fish oil inhibited the biohydrogenation of both linoleic and linolenic acids, causing the accumulation of a number of intermediates. They also suggested that both non-esterified EPA and DHA, but not fish oil, inhibited the growth and linoleic acid isomerase activity of $B$. fibrisolvens. Based on Wąsowska et al. (2006) and Maia et al. (2010) findings, EPA and DHA were more toxic than linoleic acid. This could explain the lack of effect in the case of NES addition in the present study. In spite of the obtained decrease in $B$. fibrisolvens relative proportion, in the current study with NEF and NEB, the inhibition of biohydrogenation was not applicable in case of resulted intermediates (e.g., vaccenic acid, cis-9 trans-11 C18:2), which suggest that the form of the supplemented oils could interfere with the obtained fatty acid proportion.

Khiaosa-ard et al. (2010) performed in vitro lipid emulsification to improve fatty acid distribution in biohydrogenation. They demonstrated that only 3 min dispersing linoleic acid in an ultrasonic bath could severely bias the resulting fatty acid proportion. They suggested that the small fatty acid droplets formed in the stable emulsions with sonication tended to stay in the liquid phase rather than attach to feed particles, which could lower the occurrence of both lipolysis and biohydrogenation in the fermentation fluid. In the present study the aims were different though; we initially aimed to disperse oils rich in PUFA in water, which would increase the possibility of using this supplement in the drinking water given to dairy cattle, and successively provide nanoemulsified oils during the day. That is why in the current experiment performed with the use of RUSITEC system, we intentionally added the prepared nanoemulsified oil blend directly to the incubation fluid instead of mixing it with the feed. This was done to simulate our initial idea of adding the nanoemulsion to the drinking water for dairy cattle. In the present study, the nanoscale droplets of the oil blend negatively affected the biohydrogenation intermediates proportion (vaccenic acid and conjugated linoleic acid) without affecting the total bacterial population. Generally, the toxicity of PUFA rich oils on rumen microorganisms is a physicochemical process. Fatty acids form adsorption layers around the bacterial cells which result in altered cell permeability and decreased nutrient uptake. The findings of Khiaosaard et al. (2010) as well as the unnoticed effect of the nanoemulsified oils on total bacteria in the present study could suggest that the nanoscale diameter of the oil blend droplets inhibited the bacterial chemical actions without affecting the cellular structure of the ruminal bacteria. However, in NEF and NEB treatments the toxicity of PUFA on rumen bacteria was noticed with the changes in the relative proportions of some rumen bacterial species. This modulation of the relative proportions of some rumen bacteria assumed that some oils in the form of nanoemulsions could maintain their inner potential toxic effect of decreasing ruminal bacterial populations. Anyway, rumen microorganisms' activity is affected by several factors, showing a non-uniform response toward supplementation of oils rich in UFA in the in vitro conditions (Cieślak et al., 2013).

As presented it seems that nanoemulsion technology helps to preserve higher proportions of PUFA in comparison to the control diet. This finding could be due to the direct inhibition of ruminal lipolysis and/or biohydrogenation which consequently preserves a high proportion of PUFA from being saturated under the biohydrogenation condition. However, according to Bauchart et al. (1990), two different metabolic activities of the biohydrogenation bacteria towards UFA, especially linoleic acid, should be highlighted: firstly, the extensive biohydrogenation of UFA, and secondly, the protection of these UFA from biohydrogenation by the uptake and incorporation into cellular free fatty acids. This lead us to another assumption; due to the fact that nanoemulsified form of used oil is in nanodroplets size, the permeability or uptake of this fatty acid by the bacterial cell, and, consequently a preservation of higher proportions of UFA from being hydrogenated to SFA, could be increased.

\section{Conclusions}

Nanoemulsified oils have the ability to preserve polyunsaturated fatty acids from being saturated in the biohydrogenation environment, without affecting the total bacterial or protozoan count. However, in the present study, a negative effect of nanoemulsions on the relative proportion of the biohydrogena- 
tion bacteria at the presence of fish oil suggests that nanodroplets size of the added oil did not prohibit the toxicity of long chain unsaturated fatty acids (UFA). Conversely, the nanoemulsified form of soyabean oil (5\% on dry matter basis) positively modulated the UFA proportion of ruminal culture without negatively affecting the rumen fermentation and rumen microorganisms. These findings suggest that the nanoemulsion process decreased the possible toxicity of the soyabean oil supplemented at high level on rumen microorganisms, which, in our opinion, could represent a promising supplement in dairy cattle nutrition that requires further investigation. Moreover, additional research is needed mainly to highlight the different effects of the prepared nanoemulsions on the rumen fermentation and fatty acid modulation under farm conditions.

\section{Acknowledgements}

The authors would like to thank Emilia PersKamczyc from Institute of Dendrology Polish Academy of Sciences, Parkowa 5, 62 - 035 Kórnik (Poland) for her valuable assistance with statistical analyses. The present experiment was financed by the Poznan University of Life Sciences Research Grants for Young Researchers, Nos. 507.533.13 and 507.533.42. The study scheme was a part of M. ElSherbiny general mission $(\mathrm{PhD})$ proposal financed by the Cultural Affairs and Missions Sectors, Ministry of Higher Education, Egypt.

\section{References}

AbuGhazaleh A.A., Ishlak A., 2014. Effects of incremental amounts of fish oil on trans fatty acids and Butyrivibrio bacteria in continuous culture fermenters. J. Anim. Physiol. Anim. Nutr. 98, 271-278

Bauchart D., Legay-Carmier F., Doreau M., Gaillard B., 1990. Lipid metabolism of liquid-associated and solid-adherent bacteria in rumen contents of dairy cows offered lipid-supplemented diets. Brit. J. Nutr. 63, 563-578

Beam T.M., Jenkins T.C., Moate P.J., Kohn R.A., Palmquist D.L., 2000. Effects of amount and source of fat on the rates of lipolysis and biohydrogenation of fatty acids in ruminal contents. J. Dairy Sci. 83, 2564-2573

Boerman J.P., Lock A.L., 2014. Effect of unsaturated fatty acids and triglycerides from soybeans on milk fat synthesis and biohydrogenation intermediates in dairy cattle. J. Dairy Sci. 97, 7031-7042

Cieślak A., El-Sherbiny M., Szczechowiak J., Kowalczyk D., PersKamczyc E., Bryszak M., Szulc P., Jóźwik A., SzumacherStrabel M., 2015. Rapeseed and fish oil mixtures supplied at low dose can modulate milk fatty acid composition without affecting rumen fermentation and productive parameters in dairy cows. Anim. Sci. Pap. Rep. 33, 357-372
Cieślak A., Váradyová Z., Kišidayová S., Jalč D., Szumacher-Strabel M., 2013. Effect of diets with fruit oils supplements on rumen fermentation parameters, fatty acid composition and methane production in vitro. J. Anim. Feed Sci. 22, 26-34

Czerkawski J.W., Breckenridge G., 1977. Design and development of a long-term rumen simulation technique (Rusitec). Brit. J. Nutr. 38, 371-384

El-Sherbiny M., Cieslak A., Pers-Kamczyc E., Szczechowiak J., Kowalczyk D., Szumacher-Strabel M., 2016. Short communication: A nanoemulsified form of oil blends positively affects the fatty acid proportion in ruminal batch cultures. J. Dairy Sci. 99, 399-407

Ericsson M., Hanstorp D., Hagberg P., Enger J., Nyström T., 2000. Sorting out bacterial viability with optical tweezers. J. Bacteriol. 182, 5551-5555

Fathi M., Mozafari M.R., Mohebbi M., 2012. Nanoencapsulation of food ingredients using lipid based delivery systems. Trends Food Sci. Technol. 23, 13-27

Ghosh V., Mukherjee A., Chandrasekaran N., 2014. Eugenol-loaded antimicrobial nanoemulsion preserves fruit juice against, microbial spoilage. Colloid. Surface B 114, 392-397

Hellwing A.L.F., Sørensen M.T., Weisbjerg M.R., Vestergaard M., Lund P., 2012. Can rapeseed lower methane emission from heifers? Acta Agr. Scand. Sect. A - Anim. Sci. 62, 259-262

Ishlak A., AbuGhazaleh A.A., Günal M., 2014. Short communication: Effect of blackberry and pomegranate oils on vaccenic acid formation in a single-flow continuous culture fermentation system. J. Dairy Sci. 97, 1067-1071

IUPAC, 1987. Preparation of the Fatty Acid Methyl Esters. Standard Methods for the Analysis of Oils, Fats and Derivatives. Method 2.301. Blackwell Scientific Publications. Oxford (UK), pp. 123-129

Kentish S., Wooster T.J., Ashokkumar M., Balachandran S., Mawson R., Simons L., 2008. The use of ultrasonics for nanoemulsion preparation. Innov. Food Sci. Emerg. Technol. 9, 170-175

Khiaosa-ard R., Leiber F., Soliva C.R., 2010. Methods of emulsifying linoleic acid in biohydrogenation studies in vitro may bias the resulting fatty acid profiles. Lipids 45, 651-657

Lakalayeh G.A., Faridi-Majidi R., Saber R., Partoazar A., Mehr S.E., Amani A., 2012. Investigating the parameters affecting the stability of superparamagnetic iron oxide-loaded nanoemulsion using artificial neural networks. AAPS Pharm. Sci. Tech. 13, 1386-1395

Lanier J.S., Corl B.A., 2015. Challenges in enriching milk fat with polyunsaturated fatty acids. J. Anim. Sci. Biotechnol. 6, 26, doi:10.1186/s40104-015-0025-0

Li M., Penner G.B., Hernandez-Sanabria E., Oba M., Guan L.L., 2009. Effects of sampling location and time, and host animal on assessment of bacterial diversity and fermentation parameters in the bovine rumen. J. Appl. Microbiol. 107, 1924-1934

Maeda H., Fujimoto C., Haruki Y., Maeda T., Kokeguchi S., Petelin M., Arai H., Tanimoto I., Nishimura F., Takashiba S., 2003. Quantitative real-time PCR using TaqMan and SYBR Green for Actinobacillus actinomycetemcomitans, Porphyromonas gingivalis, Prevotella intermedia, tet $Q$ gene and total bacteria. FEMS Immunol. Med. Microbiol. 39, 81-86

Maia M.R.G., Chaudhary L.C., Bestwick C.S., Richardson A.J., McKain N., Larson T.R., Graham I.A., Wallace R.J., 2010. Toxicity of unsaturated fatty acids to the biohydrogenating ruminal bacterium, Butyrivibrio fibrisolvens. BMC Microbiol. 10, 52-62

Martínez Marín A.L., Gómez-Cortés P., Gómez-Castro G., Juárez M., Pérez-Alba L., Pérez-Hernández M., de la Fuente M.A., 2013. Time-dependent variations in milk fatty acid content of goats fed 3 different plant oils. J. Dairy Sci. 96, 3238-3246 
Mason T.G., Wilking J.N., Meleson K., Chang C.B., Graves S.M., 2006. Nanoemulsions: formation, structure, and physical properties. J. Phys. - Condens. Matter 18, R635-R666

McDougall E.I., 1948. Studies on ruminant saliva. 1. The composition and output of sheep's saliva. Biochem. J. 43, 99-109

Michalowski T., Harmeyer H., Breves G., 1986. The passage of protozoa from the reticulo-rumen through the omasum of sheep. Brit. J. Nutr. 65, 625-634

Morsy T.A., Kholif S.M., Kholif A.E., Matloup O.H., Salem A.Z.M., Abu Elella A., 2015. Influence of sunflower whole seeds or oil on ruminal fermentation, milk production, composition, and fatty acid profile in lactating goats. Asian-Australas. J. Anim. Sci. $28,1116-1122$

O'Brien M., Navarro-Villa A., Purcell P.J., Boland T.M., O'Kiely P., 2014. Reducing in vitro rumen methanogenesis for two contrasting diets using a series of inclusion rates of different additives. Anim. Prod. Sci. 54, 141-157

Patra A.K., Yu Z., 2013. Effective reduction of enteric methane production by a combination of nitrate and saponin without adverse effect on feed degradability, fermentation, or bacterial and archaeal communities of the rumen. Bioresource Technol. $148,352-360$

Potu R.B., AbuGhazaleh A.A., Hastings D., Jones K., Ibrahim S.A., 2011. The effect of lipid supplements on ruminal bacteria in continuous culture fermenters varies with the fatty acid composition. J. Microbiol. 49, 216-223

Shingfield K.J., Kairenius P., Ärölä A. et al., 2012. Dietary fish oil supplements modify ruminal biohydrogenation, alter the flow of fatty acids at the omasum, and induce changes in the ruminal Butyrivibrio population in lactating cows. J. Nutr. 142, 1437-1448

Shingfield K.J., Lee M.R.F., Humphries D.J., Scollan N.D., Toivonen V., Reynolds C.K., Beever D.E., 2010. Effect of incremental amounts of fish oil in the diet on ruminal lipid metabolism in growing steers. Brit. J. Nutr. 104, 56-66
Soliva C.R., Hess H.D., 2007. Measuring methane emission of ruminants by in vitro and in vivo techniques. In: H.P.S. Makkar, P.E. Vercoe (Editors). Measuring Methane Production from Ruminants. Springer, Dordrecht (the Netherlands), pp. 15-31

Storlien T.M., Harstad O.M., Narvaez N., Wang Y., McAllister T.A., 2012. Effects of different oils and plant extracts on in vitro ruminal methane production. Acta Agr. Scand. Sect. A - Anim. Sci. 62, 300-304

Szumacher-Strabel M., Potkański A., Kowalczyk J., Cieślak A., Czauderna M., Gubała A., Jędroszkowiak P., 2002. The influence of supplemental fat on rumen volatile fatty acid profile, ammonia and $\mathrm{pH}$ level in sheep fed standard diet. J. Anim. Feed Sci. 11, 577-587

Tangerman A., Nagengast F.M., 1996. A gas chromatographic analysis of fecal short-chain fatty acids, using the direct injection method. Anal. Biochem. 236, 1-8

Wang R.-F., Cao W.-W., Cerniglia C.E., 1997. PCR detection of Ruminococcus spp. in human and animal faecal samples. Mol. Cell. Probe. 11, 259-265

Wasowska I., Maia M.R.G., Niedźwiedzka K.M., Czauderna M., Ramalho Ribeiro J.M.C., Devillard E., Shingfield K.J., Wallace R.J., 2006. Influence of fish oil on ruminal biohydrogenation of C18 unsaturated fatty acids. Brit. J. Nutr. 95, 1199-1211

Yu Z., Morrison M., 2004. Improved extraction of PCR-quality community DNA from digesta and fecal samples. Biotechniques $36,808-812$

Zhang Z., Vriesekoop F., Yuan Q., Liang H., 2014. Effects of nisin on the antimicrobial activity of $\mathrm{D}$-limonene and its nanoemulsion. Food Chem. 150, 307-312 